as far as possible into its separate constituents in the hope that the results may be of some interest, though having no commercial value. The author will be glad to have the subject discussed by the Society, and thankful for any criticisms or suggestions regarding the work.

\title{
DOES “ARGEMONE MEXICANA” CONTAIN MORPHINE?
}

\author{
BY J. O. SCHLOTTERBECK \\ Eaceived Octulier -4, rgoi
}

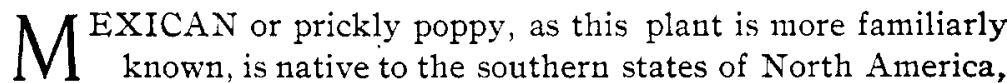
Mexico, and the West Indies, but it has spread to the north and has also been accidentally introduced by trading ships into distant tropical and subtropical lands to such an extent that it has become a troublesome weed in some localities. The plants are easily propagated from seeds which have for some time been offered by seedsmen for ornamental planting, consequently the prickly poppy has become rather cosmopolitan. The plant is striking in appearance, attains a height of 2 feet, is erect, bristly, and glaucous. The leaves are alternate, sessile, sinuately lobed, armed at the margin and under surface with very sharp prickles. The upper surface of the leaves is beautifully blotched with white. The solitary flowers are yellow, about $1 \frac{1}{4}$ inches broad, possessing a soft, bristly ovary with 4 to 6 red-tipped stigmas. When about to dehisce, to discharge the numerous finely pitted black seeds, the prickly capsule turns from green to brownish-black. When bruised, all parts of the growing plant exude a yellow, milky juice which is acrid, bitter, and of penetrating odor.

The Spanish claim emetic properties for the seeds and purgative properties for the fixed oil therefrom. Others believe the plant to possess narcotic qualities. The juice of the leaves has gained a reputation among the laity, at least, in the treatment of opacities of the cornea, pain of cephalalgia and inflammation of the eyes. Prickly poppy is official in the "Mexican Pharmacopoeia," and while reports upon its therapeutic value are very contradictory and at times fabulous, its importance has merited detailed notice of its properties and uses in the dispensatories of the United States. Considering the repute in which this plant has been held as a remedial agent among Spanish-American peoples it is rather remarkable that so little attention has been directed to its chemical study. 
Charbonnier ${ }^{1}$ made a chemical study of the leaves and capsules, and the oil of the seeds, and reported the presence of morphine. This statement has never been disputed, being still quoted in reference books to the present day. In I 877 Andrés Ortega published in the proceedings of the Escuela Nacional de Medicina de Mexico his results obtained with several species of Argemone, one of which was the plant under discussion. He operated upon 4 grams of the inspissated juice obtained by incising the unripe capsules and claims to have positively identified morphine. The only other study of this plant was made by Peckolt, ${ }^{2}$ who says that the plant is a very popular remedy in Brazil, for almost all known ailments, but that it is not at all prescribed by physicians. He separated a white alkaloid and named it argemonine. The quantity obtained was so small, however, that he could make no study of it.

The very sparse and unsatisfactory information upon the alkaloidal constituents of this plant led the writer to undertake a chemical examination with large quantities of authentic material. Ouehalf of the drug, about 20 pounds, was collected for the writer in Kansas, and the dried whole plants carefully inspected for foreign material. It was found to be free from admixture. An equal amount was grown in the university gardens. At flowering time it was collected, dried, ground, and extracted by the writer so that there seemed to be no possibility of contamination by other alkaloid-iearing drugs.

The ground plant was moistened with very dilute ammonia water and spread out in a thin layer to dry at ordinary temperature. The dry material was extracted in a large copper apparatus with chloroform until exhausted of alkaloid. The deep-green percolate was distilled for recovery of chloroform and the fatty residue digested with several portions of acidulated (acetic acid) water on the water-bath until practically no more color was extracted. The aqueous liquid was concentrated to small volume at low temperature, filtered, and set aside to cool. In a short time the deep yellow liquid had separated a magma of fine yellow needles which looked very much like berberine. It was collected on a filter and recrystallized from water several times. In its behavior with solvents and reagents, and in its physical properties,

2 Ber. d. pharm. Ges., 8, 286. 
it was identical with berberine. Chlorine water produced with a solution of this compound the characteristic: blood-red color that distinguishes berberine. Potassium iodide precipitated a hydriodide completely, leaving a colorless filtrate as is the case with berberine. Finally an acetone compound mas made according to the directions of Gaze, ${ }^{1}$ and the same quantitative yield obtained. Certainly these qualitative tests amply justify the assertion that this yellow alkaloid is none other than berberine.

Since the presence of berberine in one of the Papaveraceae is rather unusual it was feared that in spite of the great precautions taken, some berberine-bearing drug might have been accidentally mixed with the original, although the amount of berberine separated precluded any such possibility. To make doubly sure, however, just one very large plant that had been hung in the drying roon as a museum specimen was employed for a confirmatory examination. This was ground, moistened with ammonia, dried and extracted with absolute alcohol in a liter Soxhlet apparatus. The greenish filtrate after concentration and cooling separated needles of potassium nitrate. After removing all the alcohol the residue was digested with small amounts of acidulated water, the liquid filtered and set aside to evaporate spontaneously. After several days yellow crystals, answering all the well-known tests for berberine, had separated.

The filtrate from the original magma of yellow crystals was concentrated, a second small crop of berberine salt removed, then made alkaline with potassium hydroxide and slaken out several times with ether. The severai ethereal portions were filtered, reduced to small volume by distillation and then set aside in an Erlenmeyer flask. In the course of a few days small whitish warts began to accumulate on the side of the flask. After the ether had practically evaporated, the warts were dissolved in acetic acid, diluted with water, made alkaline, and shaken out again with ether. This was set aside as before and after repeating the operation several times the product became white and assumed the form of warts and small prisms, which melted at about $204^{\circ}$. Sulphuric acid gave a violet-red color with a fragment of the alkaloid upon a white slab. Erdmann's reagent gave a deep violet-blue. A beautiful green color was obtained when a little more nitric acid was added to Erdmann's reagent. The quantity 
of the alkaloid was too small to admit of further examination but the qualitative tesits mentioned together with the experience of the writer with this substance left no doubt that it was the alkaloid protopine. It is doubtless the same alkaloid which Charbonnier and Ortega imperfectly separated and called morphine. Although the color tests are not exactly the same as Peckolt obtained with his argemonine there is no question that it was protopine he had in his hands and not a new alkaloid.

The original drug marc, after having been extracted with chloroform, was percolated with hot distilled water for the purpose of removing the ammonium salts of the acids combined with the alkaloids in the plant. The dark-colored percolate was reduced to a small volume on the steam-bath and set aside to cool. A large crystalline deposit accumulated in the bottom of the vessel. This was collected upon a Buchner filter and thoroughly washed with cold water. Much of the brownish coloring-matter was removed in this manner. The residue when dry was grayish in color. It consisted partly of calcium phosphate. The acids in combination with the alkaloids have not been identified with certainty. This will be left for a future paper.

At first thought the presence of berberine in the Papaveraceae weakens the position held by the writer and others that botanical relationship to a great extent predicts chemical relationship. A comparison of the structural formulas of berberine submitted by Perkin ${ }^{1}$ with those of the opium alkaloids papaverine, narcotine, and narceine, demonstrates conclusively that the discovery of berberine in a plant of the poppy family strengthens rather than weakens this position.

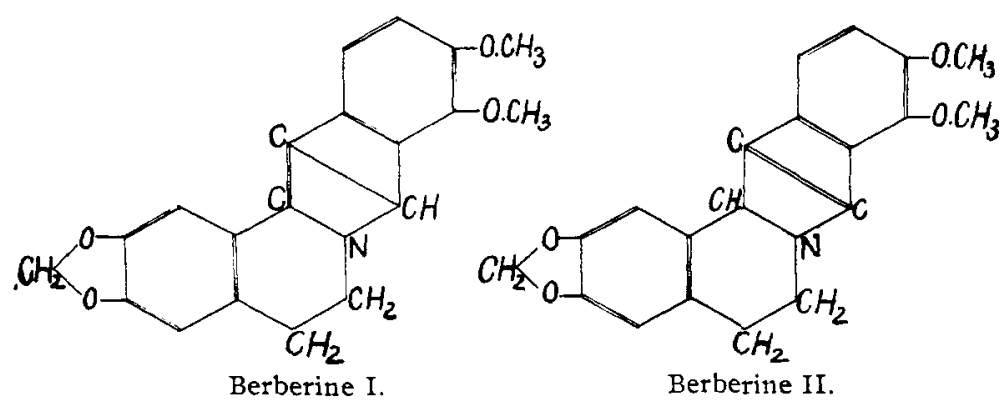

1J. Chem. Soc.,1, 991 (1890). 


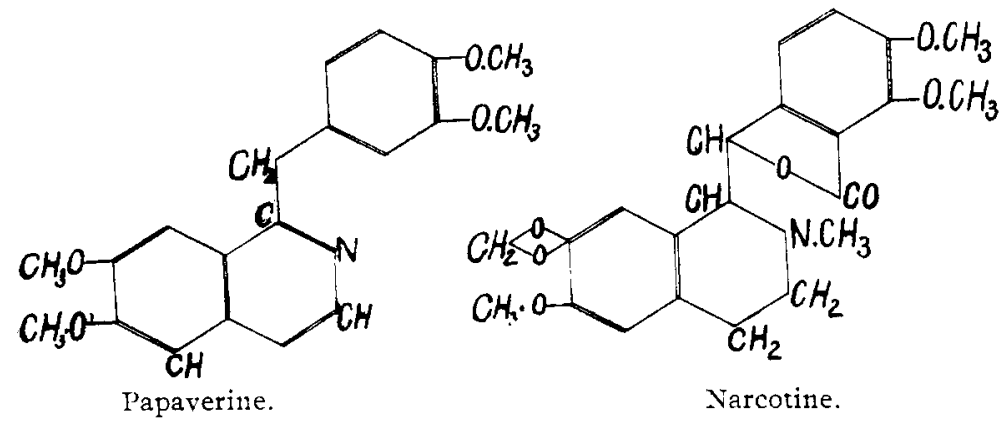

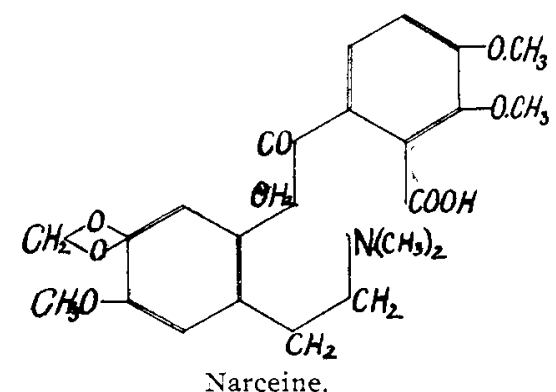

These four alkaloids together with hydrastine constitute the isochinoline group of plant alkaloids. They are, with the exception of narceine, distinct derivatives of the parent base isochinoline as is shown above. Narceine shows very close relationship to the same base. By the constitution of the above-named bases occurring in the poppy family, the botanico-chemical principle spoken of is graphically enunciated.

\section{SUIIMARY.}

I. Argemone Mexicana does not contain morphine.

2. The alkaloids of Argemone Mexicana are berberine and protopine.

3. The argemonine of Peckolt is protopine.

4. Potassium nitrate is one of the salts existing naturally in the plant.

In conclusion I wish to express my thanks to Mr. C. W. Johnson, who kindly assisted me in this investigation. 